\title{
The impact on adolescents of a Transtheoretical Model-based programme on fruit and vegetable consumption
}

\author{
Kamer Gur ${ }^{1, *}$, Saime Erol ${ }^{1}$, Hasibe Kadioglu ${ }^{1}$, Ayse Ergun ${ }^{1}$ and Rukiye Boluktas ${ }^{2}$ \\ 'Department of Public Health Nursing, Marmara University, 146418588 Maltepe/Istanbul, Turkey: ${ }^{2}$ Division of \\ Nursing, Istanbul Zaim University, Istanbul, Turkey
}

Submitted 14 May 2018: Final revision received 13 March 2019: Accepted 19 March 2019: First published online 7 June 2019

\begin{abstract}
Objective: The present study aimed to evaluate the impact of a Transtheoretical Model-based programme titled 'Fruit \& Vegetable-Friendly' on the fruit and vegetable (F\&V) consumption of adolescents.

Design: A quasi-experimental study. The 'Fruit \& Vegetable-Friendly', a multicomponent intervention based on the Transtheoretical Model, was completed in eight weeks. The data were collected one week before the intervention, one week after the completion of the intervention and six months after the post-test with an F\&V intake questionnaire and the stages of change, processes of change $(\alpha=0.91)$, situational self-efficacy $(\alpha=0.91)$ and decisional balance $(\alpha=0.90$ for pros, $\alpha=0.87$ for cons) scales. Data were analysed with the Friedman, Wilcoxon and marginal homogeneity tests.

Setting: A public secondary school in Istanbul, Turkey.

Participants: Seven hundred and two adolescents.

Results: The mean (SD) F\&V intake of adolescents in the passive stages rose from the daily average at the time of the pre-test of $3.40(1.79)$ portions to $5.45(2.54)$ portions on the post-test and to $5.75(2.70)$ portions on the follow-up test $(P<0.01)$. While the students in the passive stages represented $41.6 \%$ of the participants prior to the programme, this rate fell to $23.7 \%$ at the post-test and to $22.7 \%$ at the follow-up. Students in the active stages first represented $58.5 \%$ of the participants; this rate rose to $76.4 \%$ at the post-test and to $77.2 \%$ at the follow-up test. Conclusions: The programme was effective in increasing the amount of F\&V the adolescents consumed on a daily basis.
\end{abstract}

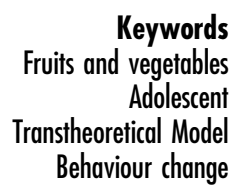

Increased consumption of fruits and vegetables (F\&V) worldwide could reduce heart disease, stroke and some cancers by 31, 19 and 12-20\%, respectively ${ }^{(1)}$. Additionally, it has been reported that a higher level of fruit or green leafy vegetable intake is associated with a significantly reduced risk of type 2 diabetes ${ }^{(2)}$. Because of this, and particularly for healthy nutrition, the food groups of fruits and vegetables must be treated as a separate topic and duly emphasized ${ }^{(3,4)}$.

Studies have shown that only $10-20 \%$ of students consume five portions of F\&V daily ${ }^{(5-7)}$. Data from the Youth Risk Behavior Survey (YRBS) of the Centers for Disease Control and Prevention have suggested that $5.2 \%$ of students do not eat fruits and $6.7 \%$ do not eat vegetables, and that only $14.8 \%$ eat three or more portions of vegetables daily and $20.0 \%$ consume fruit or fresh fruit juice daily $^{(8)}$.
It is important to understand why young people do not consume adequate amounts of F\&V and how fruit and vegetable (F\&V) intake can be increased. This is where behavioural change theories and the planning of model-based interventions geared to change behaviour can be quite beneficial. To enhance the success of studies aiming at encouraging behavioural changes in adolescents, programmes based on various theories and models have been recommended. One of these models, the Transtheoretical Model (TTM), was first developed by Prochaska and DiClemente ${ }^{(9)}$ to facilitate behavioural change in the context of cigarette smoking but was later applied to F\&V consumption by Di Noia et al. ${ }^{(10)}$.

The fundamental aim of the present study was to evaluate whether a programme titled 'Fruit \& VegetablesFriendly' (F\&V-F) based on the TTM would have an impact on increasing the intake of $\mathrm{F} \& \mathrm{~V}$ among adolescents. 


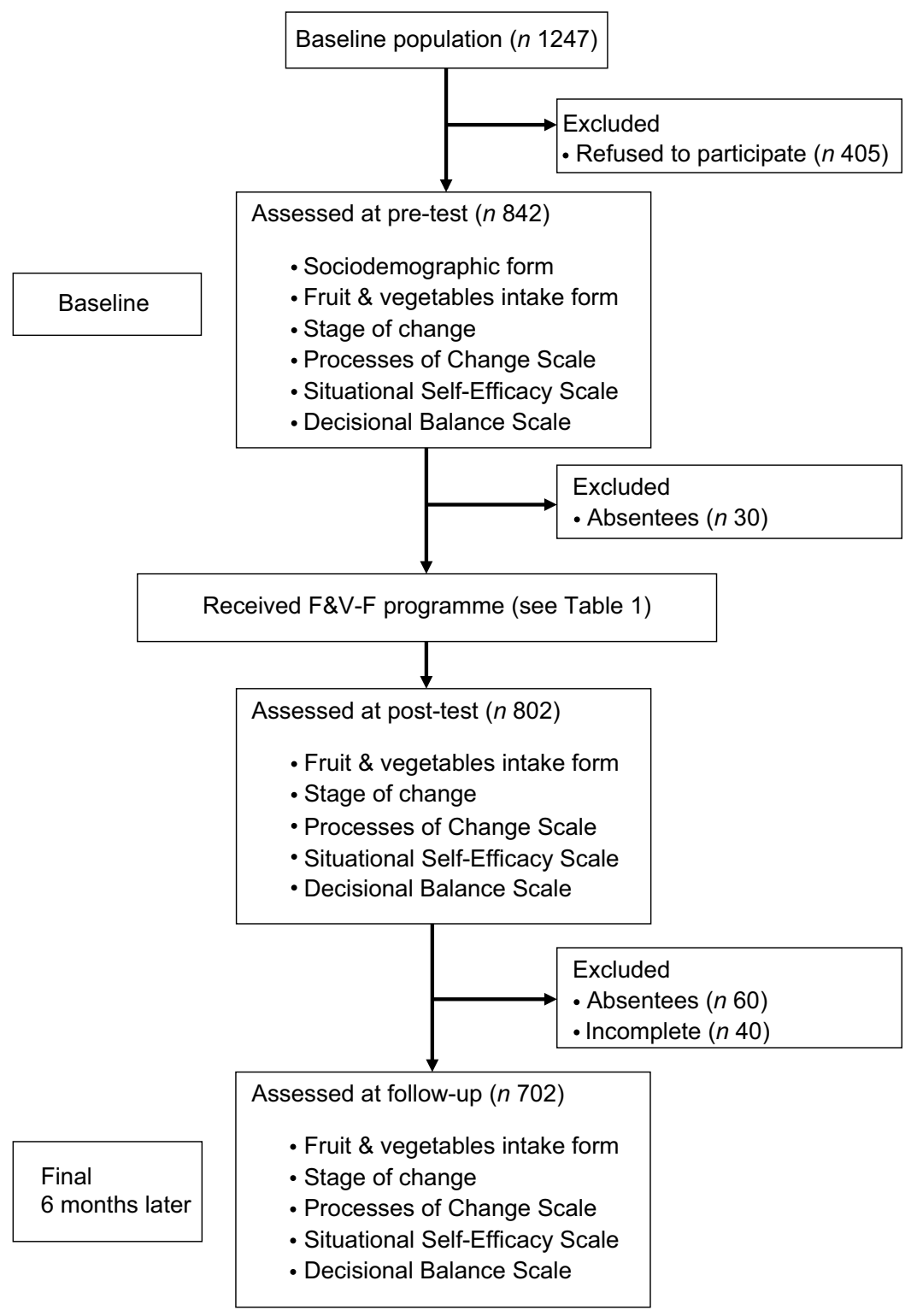

Fig. 1 Process of the study (F\&V-F, 'Fruit \& Vegetables-Friendly')

\section{Methods}

\section{Design}

The study was of pre-test/post-test single-group quasiexperimental design.

\section{Sample}

The participants in the study were adolescents ( $n$ 1247) in grades 5-8 enrolled in a public primary school in a district of Istanbul during the academic year 2013-2014. The study was ultimately completed with 702 pupils after the exclusion of those who did not wish to participate, students absent from school on the day of data collection, and students who handed in incomplete questionnaires (Fig. 1).

\section{Measures}

Data were collected on a self-reporting basis in the students' own classrooms, with students completing the following measures.

\section{Sociodemographics}

A sociodemographic form was used to collect information on students' age, gender and grade.

\section{Fruit and vegetable intake}

The F\&V intake form contained two questions on whether fruits and vegetables could be found at home and at school (with 'yes' and 'no' answers). Additionally, the form included a table explaining what one portion of vegetables or one portion of fruit meant (e.g. 1 large carrot $=1$ portion, 1 medium-sized pear $=1$ portion). Based on cultural and 
geographical factors, sixteen different types of fruits and eleven kinds of vegetables most commonly consumed were provided. The participants were asked to indicate on the table how many portions of these fruits and vegetables they ate on average on a daily basis.

\section{Transtheoretical Model stages of change}

The stages of change, which form the nuclear structure of the TTM, consists of a single question with five choices. Here, an assessment is made of how long students who eat five portions of F\&V daily have been doing this (one month or six months) and, in the case of those who do not eat this amount, what their intentions are about starting and when they intend to do so. The stages of change are as follows.

1. Pre-contemplation: 'I don't eat five portions of fruit and vegetables daily; I am not thinking of doing so in the next one month'.

2. Contemplation: 'I don't eat five portions of fruit and vegetables daily but I am thinking of doing so in the next six months'.

3. Preparation: 'I don't eat five portions of fruit and vegetables daily but I am thinking of doing so in the next one month'.

4. Action: 'I have been eating five portions of fruit and vegetables daily for the last one month'.

5. Maintenance: 'I have been eating five portions of fruit and vegetables daily for more than six months'.

\section{Processes of Change Scale}

The Processes of Change Scale (PCS) was developed by Di Noia et $a l .^{(10)}$ and Saime et ${ }^{\left({ }^{(11)}\right.}$ adapted the scale into the Turkish language (Cronbach's $\alpha=0.91$ ). The scale has nineteen items and two subscales, which are defined as Cognitive Processes and Behavioural Processes. The highest score possible on the scale is 95; the lowest is 19. Higher scores on the scale indicate that the chance of successfully achieving change is high.

\section{Situational Self-Efficacy Scale}

The Situational Self-Efficacy Scale (SSES) was developed by Di Noia et $a l^{(10)}$ and indicates the confidence an individual has that he/she will be able to start a special kind of behaviour when confronted with challenging situations. Self-efficacy is especially effective in the TTM stages of action and maintenance. Kadioglu et $a l .^{(12)}$ adapted the scale to the Turkish language (Cronbach's $\alpha=0.91$ ). The scale consists of seventeen items and three subscales identified as Positive Social Situations, Negative Affect Situations and Difficult Situations. The highest score possible on the scale is 85; the lowest is 17 . The higher the score on the SSES, the more successful is the individual in achieving behavioural change.

\section{Decisional Balance Scale}

The Decisional Balance Scale (DBS) sets forth the pros and cons of changing a behaviour. Pros represent the positive aspects of changing a behaviour; the cons reflect the barriers standing in the way of change. Ergün et al. ${ }^{(13)}$ adapted the model into the Turkish language (Cronbach's $\alpha=0.90$ for pros, 0.87 for cons). The scale is divided into thirtyone items comprising two subscales of Pros and Cons.

\section{Intervention programme: 'Fruit \& Vegetables- Friendly'}

F\&V-F was created according to the TTM five stages of change and contains multiple intervention components for students and their families. This programme contained different activities and materials (health education, F\&V intake diaries, letters to families to elicit their collaboration, sale of F\&V in the school canteen and similar endeavours). The aim of the F\&V intake diaries, which was a part of the intervention, was to have the students record in their food diaries the number of portions of fruits and the number of portions of vegetables they ate daily.

Health education was provided by the research team in the classroom. In addition, counselling was given to individuals and groups in the health office. As part of this counselling, the F\&V intake diaries the students filled out were first checked and then a card game was played in small groups in order to explain the benefits of eating F\&V and the nutrients contained in these foods. The students were reminded that F\&V were available for sale in the school canteen and encouraged to benefit from these. They were also told to remind their parents to put F\&V in accessible places at home and urged not to forget that they had agreed to eat more F\&V in line with the F\&V-F programme (Table 1).

The TTM-based programme was held for eight weeks. The sale of $F \& V$, however, continued until the follow-up test, and the posters and announcements, drawings and compositions continued to be exhibited in the school corridors. A pre-test was administered one week before the intervention, a post-test one week following the completion of the programme and a follow-up test was implemented six months after the post-test. The testing took place before the beginning of summer vacation (Table 1).

\section{Analysis}

Statistical analyses were carried out using the statistical software package SPSS Statistics for Windows, version 17. Descriptive statistics were used to analyse the characteristics of the sample. Since the data did not demonstrate normal distribution, non-parametric tests were employed. Data analysis was carried out using the Friedman, Wilcoxon and marginal homogeneity tests. The comparisons of average F\&V consumption and DBS scores on the pre-test/post-test/follow-up were assessed with the Friedman test; the pre-test/post-test/follow-up test comparisons were assessed with the Friedman test. The Wilcoxon test was used in the evaluation of matched pairs. The scores of the adolescents on the pre-test, post-test, follow-up and post-follow-up in terms of $\mathrm{F} \& \mathrm{~V}$ portions consumed daily in the various TTM stages of change were compared with the two-tailed marginal homogeneity test for categorical data. 
Table 1 Features of the 'Fruit \& Vegetables-Friendly' (F\&V-F) programme containing multicomponent interventions

\begin{tabular}{|c|c|}
\hline Characteristics of stage & Purpose of F\&V-F programme \\
\hline $\begin{array}{l}\text { Pre-contemplation: } \\
\text { - Not aware of the problem } \\
\text { - No intention to change behaviour } \\
\text { - Resistant to change, unmotivated } \\
\text { and not ready for health } \\
\text { improvement programmes }\end{array}$ & $\begin{array}{l}\text { Raising awareness about the relationship } \\
\text { between eating five portions of F\&V daily } \\
\text { and the individual's dreams about the future, } \\
\text { goals, academic achievement and health } \\
\text { Calling attention to eating five portions } \\
\text { of F\&V daily }\end{array}$ \\
\hline
\end{tabular}

\section{Contemplation:}

- Aware of the existence of the problem

- Is ambivalent

- Thinks a change can be made

- Sees, but...

Raising awareness of the benefits of change

Increasing self-efficacy

Raising awareness of the barriers to change
Attaining the needed skills and resources for consuming five portions of F\&V daily

Removing the barriers

Starting the change

ss about the choices

- Makes a plan to change

- Sees, but...

- Really ready...

Action:

- Has gone into action

- Not stable as yet

- At risk of relapsing at any moment

- Doing it, but fragile ...

Maintenance:

- Less likely to be affected by the barriers to F\&V consumption

- The individual's self-confidence has grown about whether the change can be maintained

- Maintenance...

Making it easier to adapt to the plan of change

Putting into practice the change plan schedule
Intervention

Posters and announcements were posted in the classrooms and school corridors

The F\&V-F programme was introduced at a school meeting

F\&V consumption diaries were distributed

A card game was played to promote the pros of eating $\mathrm{F} \& \mathrm{~V}$ and explain their various features

Health education was offered on the benefits to the human body of F\&V (antioxidants, vitamins, high-fibre, low-fat and low-energy diet)

Education was provided on where F\&V stand on the food pyramid and how much they should be eaten

Students were asked to record in their food diaries the number of portions of fruits and the number of portions of vegetables they ate daily

Letters were sent out to the families to request their cooperation in the programme

The school canteen started to sell fruits Information cards were sent out to the parents. Families were asked to set out F\&V at home in spots where the student could see and reach them and to prepare alternative F\&V menus together with their children

The students were asked to draw pictures and write compositions about 'The Place of Fruit and Vegetables in our Lives'

The change plan was drawn up together with the students

An agreement was signed on the implementation of the plan that was drawn up

The F\&V intake diaries were checked

F\&V were made available for consumption at school snack time

The adolescents shared with their classmates the F\&V menus that they had prepared at home with their parents

The school canteen continued to sell F\&V

Preventing relapses and reinforcing the success attained in the action stage Ensuring that the change in behaviour is

A ceremony was organized with the participation of the school administrators in honour of the students who succeeded in eating five or more portions of F\&V daily:

- All participants were given an F\&V-F achievement certificate

- Pencils with F\&V reminders were handed out and the students were asked to use them regularly

- All of the drawings and compositions created by the students on the topic of 'The Place of Fruits and Vegetables in our Lives' were exhibited along the school corridors
Significance was set at $P<0.05$ with the confidence interval estimated to be at the $95 \%$ level.

\section{Ethical considerations}

Permission for the study was obtained from the school administration. The Health Sciences Faculty granted approval for the study (B.30.2.YTU.029.12.00/5300-483). The families were informed about the programme through the school administration and their consent was obtained. Each participant was informed about the purpose and privacy of the study. The consent of the children was obtained.

\section{Results}

The mean age of the participating adolescents was 12.02 (SD 1.18) years (minimum-maximum: 9-15 years); 54.8\% 
Table 2 Comparison of average portions of fruits and vegetables consumed daily at the pre-test, post-test and follow-up test, by stage of change, among adolescents ( $n 702)$ in grades 5-8 from a public primary school in Istanbul, Turkey, receiving the 'Fruit \& Vegetables-Friendly' programme during the academic year 2013-2014

\begin{tabular}{|c|c|c|c|c|c|c|c|c|c|c|c|c|c|c|c|c|}
\hline \multirow{3}{*}{$\begin{array}{l}\text { Stage student was in } \\
\text { before intervention }\end{array}$} & \multirow[b]{3}{*}{ Servings/d } & \multirow{2}{*}{\multicolumn{2}{|c|}{$\begin{array}{l}\text { Pre-test } \\
\text { (a) }\end{array}$}} & \multirow{2}{*}{\multicolumn{2}{|c|}{$\begin{array}{l}\text { Post-test } \\
\text { (b) }\end{array}$}} & \multirow{2}{*}{\multicolumn{2}{|c|}{$\begin{array}{l}\text { Follow-up } \\
\text { (c) }\end{array}$}} & \multicolumn{9}{|c|}{ Differences } \\
\hline & & & & & & & & \multicolumn{3}{|c|}{$(c-a)$} & \multicolumn{2}{|c|}{$(a-b)$} & \multicolumn{2}{|c|}{$(a-c)$} & \multicolumn{2}{|c|}{$(b-c)$} \\
\hline & & Mean & SD & Mean & SD & Mean & SD & Mean & $\chi^{2}$ & $P$ & $Z$ & $P$ & $Z$ & $P$ & $Z$ & $P$ \\
\hline \multirow{3}{*}{$\begin{array}{l}\text { Pre-contemplation } \\
\quad(n 14)\end{array}$} & Fruits & 0.2 & 0.4 & $2 \cdot 0$ & 1.4 & $2 \cdot 3$ & $1 \cdot 6$ & $2 \cdot 1$ & $17 \cdot 6$ & $<0.01$ & 3.0 & $<0.01$ & 3.0 & $<0.01$ & 0.90 & 0.364 \\
\hline & Vegetables & 0.4 & 0.5 & 1.4 & 0.9 & $2 \cdot 0$ & $1 \cdot 2$ & 1.6 & 14.9 & $<0.05$ & 2.5 & $<0.01$ & 2.9 & $<0.01$ & $2 \cdot 0$ & $<0.05$ \\
\hline & F\&V & 0.6 & 0.5 & 3.4 & $2 \cdot 2$ & $4 \cdot 3$ & $2 \cdot 6$ & $3 \cdot 7$ & $19 \cdot 2$ & $<0.01$ & 3.0 & $<0.01$ & $3 \cdot 1$ & $<0.01$ & 1.4 & 0.140 \\
\hline \multirow{3}{*}{$\begin{array}{l}\text { Contemplation } \\
(n 89)\end{array}$} & Fruits & $1 \cdot 0$ & $0 \cdot 1$ & $2 \cdot 3$ & $1 \cdot 3$ & $2 \cdot 6$ & 1.5 & $1 \cdot 6$ & $75 \cdot 1$ & $<0.01$ & $6 \cdot 5$ & $<0.01$ & $6 \cdot 6$ & $<0.01$ & $2 \cdot 0$ & $<0.05$ \\
\hline & Vegetables & 1.0 & 0.2 & $2 \cdot 0$ & 1.4 & $2 \cdot 4$ & 1.5 & 1.4 & $63 \cdot 0$ & $<0.01$ & $5 \cdot 7$ & $<0.01$ & 6.5 & $<0.01$ & $2 \cdot 3$ & $<0.05$ \\
\hline & F\&V & $2 \cdot 0$ & 0.1 & 4.3 & 2.6 & $5 \cdot 0$ & $2 \cdot 8$ & $3 \cdot 0$ & $79 \cdot 3$ & $<0.01$ & $6 \cdot 4$ & $<0.01$ & 6.9 & $<0.01$ & $2 \cdot 6$ & $<0.01$ \\
\hline \multirow{3}{*}{$\begin{array}{l}\text { Preparation } \\
(n 189)\end{array}$} & Fruits & $2 \cdot 0$ & 0.6 & $2 \cdot 9$ & 1.3 & $3 \cdot 1$ & 1.4 & $1 \cdot 1$ & 83.9 & $<0.01$ & $7 \cdot 7$ & $<0.01$ & $8 \cdot 3$ & $<0.01$ & 1.4 & $<1.43$ \\
\hline & Vegetables & 1.5 & 0.6 & $2 \cdot 6$ & 1.4 & $2 \cdot 8$ & 1.4 & $1 \cdot 3$ & $104 \cdot 0$ & $<0.01$ & $8 \cdot 2$ & $<0 . .01$ & $8 \cdot 8$ & $<0.01$ & $1 \cdot 6$ & 0.105 \\
\hline & F\&V & 3.5 & 0.5 & 5.5 & $2 \cdot 4$ & $5 \cdot 9$ & $2 \cdot 6$ & $2 \cdot 4$ & $115 \cdot 8$ & $<0.01$ & $9 \cdot 1$ & $<0.01$ & 9.5 & $<0.01$ & 1.4 & 0.150 \\
\hline \multirow[t]{3}{*}{ Action (n237) } & Fruits & $3 \cdot 2$ & 0.9 & 3.4 & $1 \cdot 3$ & 3.4 & $1 \cdot 3$ & 0.2 & $15 \cdot 6$ & $<0.01$ & 3.4 & $<0.01$ & $2 \cdot 6$ & $<0.01$ & 0.56 & 0.57 \\
\hline & Vegetables & $2 \cdot 7$ & 0.8 & $3 \cdot 1$ & 1.4 & $3 \cdot 2$ & 1.4 & 0.5 & $17 \cdot 0$ & $<0.01$ & 4.0 & $<0.01$ & 4.8 & $<0.01$ & $1 \cdot 1$ & 0.25 \\
\hline & F\&V & $5 \cdot 8$ & 0.9 & $6 \cdot 5$ & 2.5 & $6 \cdot 6$ & $2 \cdot 5$ & $0 \cdot 8$ & $23 \cdot 6$ & $<0.01$ & 4.3 & $<0.01$ & 4.5 & $<0.01$ & 0.38 & 0.701 \\
\hline \multirow{3}{*}{$\begin{array}{l}\text { Maintenance } \\
\quad(n 173)\end{array}$} & Fruit & $4 \cdot 6$ & 0.6 & $4 \cdot 0$ & $1 \cdot 3$ & $4 \cdot 0$ & $1 \cdot 3$ & -0.6 & 34.4 & $<0.01$ & 5.4 & $<0.01$ & $5 \cdot 6$ & $<0.01$ & 0.18 & 0.857 \\
\hline & Vegetable & $4 \cdot 3$ & 0.7 & $3 \cdot 8$ & $1 \cdot 3$ & 3.7 & $1 \cdot 3$ & -0.7 & $24 \cdot 6$ & 0.492 & 4.5 & $<0.01$ & 5.4 & $<0.01$ & 1.3 & 0.190 \\
\hline & $F \& V$ & 8.9 & 1.0 & 7.8 & 2.4 & $7 \cdot 7$ & $2 \cdot 2$ & $-1 \cdot 2$ & 31.8 & $<0.01$ & $5 \cdot 3$ & $<0.01$ & 6.2 & $<0.01$ & 0.59 & 0.552 \\
\hline
\end{tabular}

$\chi^{2}$, Friedman test; $Z$, Wilcoxon test; F\&V, fruits and vegetables.

were girls, $45.2 \%$ were boys. Of the students, $29.9 \%$ were in the fifth, $26.2 \%$ in the sixth, $20.9 \%$ in the seventh and $22.9 \%$ were in the eighth grade. Prior to the programme, $12.7 \%$ of the adolescents stated that they had no F\&V in the house when they wanted to eat some and that there was none at school.

\section{Comparison of fruit and vegetable average portions consumed daily in the stages of change}

The comparison of the students' F\&V consumption in the pre-test, post-test and follow-up period according to their stage of change prior to the F\&V-F programme is shown in Table 2.

The difference between the pre-test and the follow-up administered six months after the intervention was 3.7 portions/d in students who were in the precontemplation stage, 3.0 portions/d in those in the contemplation stage and 2.4 portions/d in those in the preparation stage. The difference in $F \& V$ consumption in those in the action stage was 0.8 portions/d. It was observed that in the maintenance stage, total $\mathrm{F} \& \mathrm{~V}$ consumption had decreased by 1.2 portions/d (Table 2).

\section{Stages of change}

Examining the distribution of the adolescents in the various stages of change, it can be seen that the differences between the pre-test/post-test $(P<0 \cdot 001)$, between the pre-test/follow-up $(P<0.001)$ and between the post-test/ follow-up $(P<0.01)$ indicate that the students had achieved progress in the behavioural stages of change with respect to their F\&V consumption. The percentage of students in the action and maintenance stages increased, while the percentage of students in the pre-contemplation, contemplation and preparation stages decreased. Whereas before the programme, $2.2 \%$ of the students were in the pre-contemplation and $13.0 \%$ were in the contemplation stage, those in pre-contemplation receded to $1.8 \%$ on the post-test and to $0.8 \%$ on the follow-up. The percentage of students in the contemplation stage fell to $5 \cdot 1 \%$ on the post-test but was $6.0 \%$ on the follow-up test. The percentage in the preparation stage fell from $26.4 \%$ to $16 \cdot 8 \%$ on the post-test and to $15.9 \%$ on the follow-up. In the follow-up test $32.0 \%$ of the students passed into the action stage and $45.2 \%$ into the maintenance stage. Whereas students in the action and maintenance stages represented $58.5 \%$ on the post-test, this percentage rose to $76.4 \%$ and to $77.2 \%$ on the follow-up (Fig. 2).

\section{Decisional balance}

DBS Pros scores were found to be statistically higher on the post-test and follow-up compared with the pre-test $(P \leq 0.001)$. No statistical differences were found in the mean scores of the Cons subscale on the pre-test, post-test and follow-up tests $(P>0 \cdot 05$; Table 3$)$.

\section{Processes of change}

On the post-test and follow-up, the PCS total mean scores, Cognitive Processes and Behavioural Processes mean scores were statistically higher compared with the pre-test $(P<0.001)$. There was no difference between the post-test and the follow-up test $(P>0 \cdot 05$; Table 3$)$. 
Table 3 Comparison of scores on the Decisional Balance Scale, Processes of Change Scale and Situational Self-Efficacy Scale at the pre-test, post-test and follow-up test among adolescents ( $n 702)$ in grades 5-8 from a public primary school in Istanbul, Turkey, receiving the 'Fruit \& Vegetables-Friendly' programme during the academic year 2013-2014

\begin{tabular}{|c|c|c|c|c|c|c|c|c|c|c|c|c|c|c|}
\hline \multirow[b]{3}{*}{ TTM scale } & \multirow{2}{*}{\multicolumn{2}{|c|}{ Pre test $(a)$}} & \multirow{2}{*}{\multicolumn{2}{|c|}{ Post-test $(b)$}} & \multirow{2}{*}{\multicolumn{2}{|c|}{$\begin{array}{c}\text { Follow-up } \\
\text { test }(c)\end{array}$}} & \multicolumn{8}{|c|}{ Differences } \\
\hline & & & & & & & \multicolumn{2}{|c|}{$(c-a)$} & \multicolumn{2}{|c|}{$(a-b)$} & \multicolumn{2}{|c|}{$(a-c)$} & \multicolumn{2}{|c|}{$(b-c)$} \\
\hline & Mean & SD & Mean & SD & Mean & SD & $\chi^{2}$ & $P$ & Z & $P$ & Z & $P$ & Z & $P$ \\
\hline \multicolumn{15}{|l|}{ Decisional balance } \\
\hline Pros & $78 \cdot 72$ & $10 \cdot 30$ & $80 \cdot 04$ & $11 \cdot 31$ & $80 \cdot 78$ & $10 \cdot 75$ & $56 \cdot 56$ & 0.000 & 4.67 & 0.000 & $5 \cdot 65$ & 0.000 & 1.66 & 0.096 \\
\hline Cons & 39.07 & $11 \cdot 21$ & $40 \cdot 12$ & 14.63 & 39.54 & $15 \cdot 17$ & $2 \cdot 26$ & 0.322 & - & - & - & - & - & - \\
\hline \multicolumn{15}{|l|}{ Processes of change } \\
\hline Cognitive Processes & $28 \cdot 13$ & 5.40 & 29.44 & $5 \cdot 18$ & $29 \cdot 46$ & 5.54 & 49.97 & 0.000 & 5.99 & 0.000 & 5.49 & 0.000 & 0.34 & 0.733 \\
\hline Behavioural Processes & 41.62 & 11.05 & $45 \cdot 69$ & $10 \cdot 50$ & $45 \cdot 18$ & $12 \cdot 07$ & 61.50 & 0.000 & 8.57 & 0.000 & 6.57 & 0.000 & 0.37 & 0.708 \\
\hline Total score & $69 \cdot 75$ & 14.90 & $75 \cdot 14$ & $14 \cdot 28$ & $74 \cdot 65$ & $16 \cdot 08$ & 71.57 & 0.000 & 8.50 & 0.000 & $6 \cdot 64$ & 0.000 & 0.10 & 0.916 \\
\hline \multicolumn{15}{|l|}{ Situational self-efficacy } \\
\hline Positive Social Situations & $16 \cdot 06$ & $3 \cdot 61$ & $16 \cdot 88$ & 3.40 & $17 \cdot 09$ & 3.53 & $58 \cdot 88$ & 0.000 & 5.46 & 0.000 & 6.46 & 0.000 & 1.73 & 0.082 \\
\hline Negative Affect Situations & $25 \cdot 25$ & $9 \cdot 46$ & 28.00 & 9.85 & $27 \cdot 85$ & $10 \cdot 21$ & 37.52 & 0.000 & 5.79 & 0.000 & 5.57 & 0.000 & 0.025 & 0.000 \\
\hline Difficult Situations & $16 \cdot 57$ & $5 \cdot 64$ & $17 \cdot 21$ & $5 \cdot 88$ & $16 \cdot 90$ & $6 \cdot 31$ & 1.75 & 0.416 & - & - & - & - & - & - \\
\hline Total score & $57 \cdot 89$ & $15 \cdot 07$ & $62 \cdot 10$ & $15 \cdot 67$ & 61.85 & $16 \cdot 62$ & 24.00 & 0.000 & 5.41 & 0.000 & 4.97 & 0.000 & 0.073 & 0.942 \\
\hline
\end{tabular}

TTM, Transtheoretical Model; $\chi^{2}$, Friedman test; $Z$, Wilcoxon test.

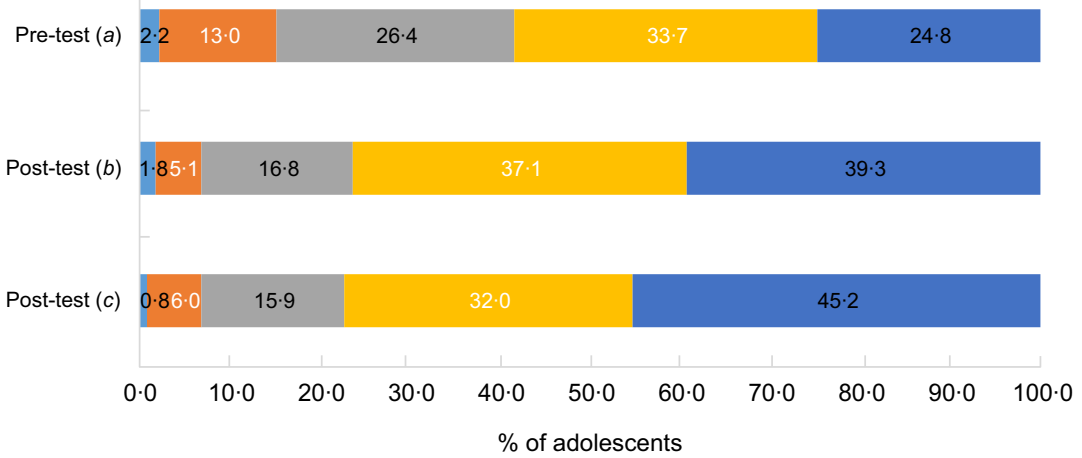

Fig. 2 (Colour online) Comparison of the changes regarding eating five portions of fruit and vegetables daily on the pre-test, post-test and follow-up test, by stage of change ( $₫$, precontemplation; $₫$, contemplation; $₫$, preparation; $₫$, action; $₫$, maintenance), among adolescents $(n 702)$ in grades 5-8 from a public primary school in Istanbul, Turkey, receiving the 'Fruit \& Vegetables-Friendly' programme during the academic year 2013-2014. Programme effect: $(a-b)$, marginal homogeneity test $=1098 \cdot 00, P<0.001 ;(a-c)$, marginal homogeneity test $=1143.00, P<0.001 ;(b-c)$, marginal homogeneity test $=732.00, P<0.01$

\section{Situational self-efficacy}

While on the pre-test, post-test and follow-up test, statistical differences were found between the total mean scores on the SSES $(P<0.001)$, the mean scores on the Positive Social Situations subscale $(P<0.001)$ and the mean scores on the Negative Affect Situations subscale $(P<0.001)$, no differences were found in the mean scores of the Difficult Situations subscale $(P>0.05)$. In the paired comparisons, the fact that there were statistical differences between the pre-test and the post-test $(P<0.001)$ and the follow-up test $(P<0.001)$ indicated that the $\mathrm{F} \& \mathrm{~V}-\mathrm{F}$ programme was effective in developing self-efficacy in the context of eating more F\&V (Table 3).

\section{Discussion}

The present study was carried out to assess the impact of the TTM-based F\&V-F programme on the stages of change, decisional balance (pros and cons), self-efficacy and processes of change with respect to adolescents' daily consumption of $\mathrm{F} \& \mathrm{~V}$.

The results of the study, which were based on the self-reporting of adolescents, showed that following the implementation of the F\&V-F programme, the adolescents had increased the amounts of their daily consumption of F\&V. It was seen that the increase in vegetable consumption among the students in the precontemplation, 
contemplation and preparation stages was between 1.6 and 1.3 portions/d, while the increase in fruit consumption was found to be between $2 \cdot 1$ and $1 \cdot 1$ portions/d. After the programme, the increase in $\mathrm{F} \& \mathrm{~V}$ consumption was greatest in the precontemplation (mean: 3.7 portions/d) and contemplation stages (mean: 3.0 portions/d). Since the F\&V consumption of the students in the action stage was adequate ( $>5$ portions/d), there was a moderate rise in this group. Since the total F\&V consumption of those in the maintenance stage was about 9 portions/d, there was a decrease of approximately 1 portion/d. Following the F\&V-F programme, it was seen that the students in the precontemplation, contemplation and preparation stages displayed increased consumption, while those in the action and maintenance stages continue to consume more than five daily portions.

In research where, as in the present study, multiplecomponent interventions were used to increase $F \& V$ intake (by including the programme in the school curriculum, eliciting the participation of parents, modifying school menus, interventions involving school cafeterias/canteens), it has been reported that increases of $0.2-1.60$ portions have been attained in F\&V daily intake ${ }^{(14-16)}$. On the other hand, in studies where only single components were employed as interventions, such as ensuring that $F \& V$ are sold in the school cafeteria, the reports have been that the increase in the daily amount of consumption has remained at the level of between 0 and 0.7 portions ${ }^{(17,18)}$. In one of two systematic reviews on interventions supporting $\mathrm{F} \& \mathrm{~V}$ intake, an average increase of 0.6 portions was reported $^{(19)}$; while in the other, an increase of 0.1-1.4 portions/d was said to have been achieved ${ }^{(20)}$. As expressed in one study that explored not general F\&V consumption but F\&V consumption at school ${ }^{(21)}$, multicomponent interventions are a more effective way of increasing F\&V consumption in schools compared with single-component interventions. In the light of these findings, it can be said that the self-reported F\&V-F programme, which is a multicomponent intervention that aims to increase $\mathrm{F} \& \mathrm{~V}$ consumption at both home and school, is on the average more effective than any other multicomponent interventions applied to increase the consumption of F\&V.

The most important points in using the TTM in the context of achieving behavioural change are designing interventions to suit the level of preparedness of the individuals involved and then to adapt them accordingly ${ }^{(22)}$. When considering the stages of change, various studies have shown that when individuals are in the action and maintenance stages, they are likely to be following better diets than individuals in the precontemplation, contemplation and preparation stages ${ }^{(23,24)}$. In addition, their F\&V consumption is likely to be at a higher level ${ }^{(23)}$. In the present study, prior to the programme, $2 \cdot 2 \%$ of the adolescents were in the precontemplation stage; in other words, they had no intention of changing the amount of their F\&V intake. Another $13.0 \%$ were in the contemplation stage; that is, although they were not consuming 5 portions $\mathrm{F} \& \mathrm{~V} / \mathrm{d}$, they were thinking of eating this amount of $\mathrm{F} \& \mathrm{~V}$ in the next six months. Among the students, $26.4 \%$ were in the preparation stage; in other words, despite the fact that they were as yet not eating 5 portions $\mathrm{F} \& \mathrm{~V} / \mathrm{d}$, they were aiming to start eating this amount in the next one month. The students in the precontemplation, contemplation and preparation stages prior to the programme constituted $41.6 \%$ of the adolescents. In contrast, $33.7 \%$ were in the action stage, which meant that they had already been consuming $\geq 5$ portions $\mathrm{F} \& \mathrm{~V} / \mathrm{d}$ for less than the last six months. Another $24.8 \%$ were in the maintenance stage, meaning that they had been eating $\geq 5$ portions $F \& V / d$ for longer than six months. The students comprising the action and maintenance steps represented $58.5 \%$. While on the post-test at the end of the programme, the percentage of students in the precontemplation stage receded to $1.8 \%$, those in the contemplation stage fell to $5.1 \%$ and those in the preparation stage to $16.8 \%$, the percentage of students in the action stage rose to $37.1 \%$ while those in the maintenance stage rose to $39.3 \%$. It was seen on the follow-up test that $32.0 \%$ of the students remained in the action stage while the percentage of students in the maintenance stage rose to $45.2 \%$. It can be concluded from these results that the F\&V-F programme set up in accordance with the principles of the TTM makes an important contribution to adolescents progressing through the stages of change. It has also been found that the programme is effective in increasing the number of students passing on from the precontemplation and preparation stages to the action and maintenance stages of change. Furthermore, one of the most promising outcomes of the F\&V-F is that a relapse is not witnessed in the follow-up period. As a matter of fact, the majority of the students were in the maintenance stage in this period. Encouraging pupils to use pencils that have a slogan written on them reminding them of eating $\mathrm{F} \& \mathrm{~V}$ and enlisting the cooperation of parents, it is thought, may be elements that prevent relapse.

When it is considered how complex lifestyle behaviour manifests itself in different individuals, the use of the TTM with all of its components gains even more importance. Although some studies have been carried out on decisional balance, self-efficacy, stages of change and F\&V intake ${ }^{(25,26)}$, most of these have concentrated mostly on the stages of change in the context of F\&V consumption $^{(27,28)}$. On the other hand, programmes directed at increasing $\mathrm{F} \& \mathrm{~V}$ consumption recommend that interventions that will make an impact on the factors that ensure change, that is, self-efficacy, decisional balance and the processes of change, must be considered ${ }^{(29)}$. What differentiates our study is that the F\&V-F programme was undertaken not only to explore the stages of change but also to include interventions that would impact decisional balance, processes of change and situational self-efficacy. In this way, we were able to produce new findings that 
exhibited the impact of the programme on the stages of changes and on decisional balance, processes of change and situational self-efficacy.

Positive social situations produce interactions that arouse positive emotions (e.g. having a good time with friends at a birthday party, enjoying a picnic). Negative affect situations are situations that cause an individual to feel bad (e.g. being in a tense atmosphere of argument, being in the presence of people one does not like, feeing sad). Difficult situations are those situations in which it is not convenient to take action (e.g. when only junk food is readily available). Similar to our study, Langenberg et $a l .{ }^{(30)}$ showed that the programme they conducted increased situational self-efficacy. Contrary to our study, however, the programme of Di Noia and Prochaska proved to be inadequate in increasing situational self-efficacy ${ }^{(31)}$. We believe that signing an agreement with the participants in our F\&V-F programme and asking them to keep a diary on their $F \& V$ consumption were beneficial steps in increasing situational self-efficacy. At the same time, the cooperative efforts of the students' families and the school canteen, we believe, also facilitated change in the adolescents.

While the programme in our study increased the perception of pros, we found that it had no effect on the students' perceptions of the cons. The strategies the programme used to reduce the perception of cons were: What were the barriers to increasing F\&V consumption? What did the young people see as barriers or cons? (for example, believing that F\&V would cause bloating and harm them, not eating them because they didn't like the smell). The programme provided advice on matters of this kind. In the light of these findings and in order to reduce the cons that prevent adolescents from consuming $F \& V$, it may be useful when conducting further studies to focus more on interventions directed at the family. Similarly, in the study of Di Noia and Prochaska ${ }^{(31)}$, it was reported that the young people did not change their perception of cons despite the interventions made to increase their $F \& V$ consumption. Meanwhile, in other TTM research ${ }^{(30)}$ conducted with low-income adults, the use of similar strategies was found effective in decreasing cons. It may have been because Langenberg et al. ${ }^{(30)}$ actively employed peer educators in their intervention. Regardless of these points, however, every programme may have strengths and weaknesses. Although our programme had many strengths, perhaps our interventions to reduce the perception of cons were weak. The present study revealed increases in the processes of change and in situational self-efficacy, but Di Noia and Prochaska ${ }^{(31)}$ have reported that the identified mediators of a TTM intervention were insufficient in enhancing self-efficacy. The differences between the findings of Langenberg et al. ${ }^{(30)}$ and Di Noia and Prochaska ${ }^{(31)}$ may be an artifact of the dissimilarities between the TTM interventions and outcome measures used in each study. Although all of the programmes were based on the TTM, the durations and intensities of each were different. The programme of Langenberg et al. ${ }^{(30)}$ was delivered over a 6-month interval and comprised three components: (i) peer-led nutrition education sessions; (ii) dissemination of printed materials (clue cards, tip sheets, recipes and activity booklets) and videotaped materials; and (iii) direct mailing of stage-tailored letters. In the programme of Di Noia and Prochaska, single-component interactive multimedia sessions were delivered via CD-ROM over a 4-week interval.

In a systematic review by Carvalho de Menezes et al., even though programmes and measuring instruments were based on the TTM, the differences between the reports make it difficult to analyse outcomes ${ }^{(28)}$. For example, the measures of cons and self-efficacy used in the Langenberg et al. study contained fewer items than did the measures used in the Di Noia and Prochaska study ${ }^{(31)}$. Or it may have been that some of the measuring tools were more sensitive to detecting change than others. All of these factors indeed make it quite difficult to discuss all of the findings obtained from the instruments developed based on the TTM. Longer interventions may prove to be more effective in reaching a conclusion.

To summarize, our findings indicate that, when compared with other studies, the F\&V-F programme delivering the multicomponent interventions that we used (diaries of F\&V consumption, printed materials such as card games, letters to families, producing drawings and compositions about the pros of $F \& V$ and their various features) was more effective in making a positive change in situational self-efficacy, the perception of pros and in the processes of change.

\section{Study limitations}

The present study is limited by the lack of a control group and the use of self-reported measures. While collecting data based on self-reporting is convenient when working with large school groups, this method may be inadequate in reflecting actual behaviour. At the same time, despite the fact that in the present study the sale of $\mathrm{F} \& \mathrm{~V}$ was introduced at the school in order to ensure F\&V consumption, the amounts sold were not considered in the analysis. Future studies may do well to include the amount of F\&V sold at school canteens as an objective criterion. Furthermore, students' self-reporting and feedback received from their parents can be analysed for consistency or correlations regarding $\mathrm{F} \& \mathrm{~V}$ consumption at home.

\section{Acknowledgements}

Acknowledgements: The authors thank the nursing students, pupils and teachers who supported this research. Financial support: This research received no specific grant from any funding agency in the public, commercial 
or not-for-profit sectors. Conflicts of interest: None. Authorship: Design of work: K.G., S.E., A.E. and H.K.; data collection: K.G.; analysis of data: H.K. and A.E.; interpretation of data: H.K., A.E., S.E., K.G. and R.B.; preparation of manuscript: K.G., H.K. and S.E.; drafting the work: H.K., A.E., S.E., K.G. and R.B.; reading and approval of final manuscript: H.K., A.E., S.E., K.G. and R.B. Ethics of human subject participation: This study was conducted according to the guidelines laid down in the Declaration of Helsinki and all procedures involving research study participants were approved by the Ethics Committee of Yeditepe University (opinion number B.30.2.YTU.029.12.00/5300-483). Written informed consent was obtained from all subjects.

\section{References}

1. Ezzati M, Lopez AD, Rodgers A et al. (editors) (2004) Comparative Quantification of Health Risks: Global and Regional Burden of Disease Attributable to Selected Major Risk Factors. Geneva: WHO.

2. Li M, Fan Y, Zhang X et al. (2014) Fruit and vegetable intake and risk of type 2 diabetes mellitus: meta-analysis of prospective cohort studies. BMJ Open $\mathbf{4}$, e005497.

3. Ha E-J \& Caine-Bish N (2009) Effect of nutrition intervention using a general nutrition course for promoting fruit and vegetable consumption among college students. $J$ Nutr Educ Behav 41, 103-109.

4. Winkleby MA \& Cubbin C (2004) Changing patterns in health behaviors and risk factors related to chronic diseases, 1990-2000. Am J Health Promot 19, 19-27.

5. Stang J \& Bayerl CT (2003) Position of the American Dietetic Association: child and adolescent food and nutrition programs. J Acad Nutr Diet 103, 887-893.

6. Vadiveloo M, Zhu L \& Quatromoni PA (2009) Diet and physical activity patterns of school-aged children. J Am Diet Assoc 109, 145-151.

7. Baş M, Altan T, Dinçer D et al. (2005) Determination of dietary habits as a risk factor of cardiovascular heart disease in Turkish adolescents. Eur J Nutr 44, 174-182.

8. Centers for Disease Control and Prevention (2009) National Youth Risk Behavior Survey Overview. Atlanta, GA: US Department of Health and Human Services, Division of Adolescent and School Health.

9. Prochaska J \& DiClemente CC (1983) Stage and processes of self-change of smoking: toward an integrative model of change. J Consult Clin Psychol 51, 390-395.

10. Di Noia J, Schinke SP, Prochaska JO et al. (2006) Application of the transtheoretical model to fruit and vegetable consumption among economically disadvantaged African-American adolescents: preliminary findings. Am J Health Promot 20, 342-348.

11. Saime E, Ergün A \& Kadığlu H (2016) Adölesanlarda MeyveSebze Tüketimi İçin Değişim Süreci Ölçeği: Güvenirlik ve Geçerlik Çalışması. Să̆lık Să̆llk Bilimleri ve Meslekleri Dergisi 3, 106-114.

12. Kadioglu H, Erol S \& Ergun A (2015) Reliability and validity of the Turkish version of the situational self-efficacy scale for fruit and vegetable consumption in adolescents. $A m J$ Health Promot 29, 273-275.

13. Ergün A, Kadıoğlu H \& Erol A (2013) Adölesan sebze meyve tüketimi Karar Alma Ölçeğinin Türkçe formunun geçerlik ve güvenirliği. In 16. Ulusal Halk Sağ lı̆̆ı Kongresi Kitabı, p. 411. [S Üner, E İrgil, H Erengin et al., editors]. Antalya: HASUDER.

14. Reinaerts E, Crutzen R, Candel M et al. (2008) Increasing fruit and vegetable intake among children: comparing long-term effects of a free distribution and a multicomponent program. Health Educ Res 23, 987-996.

15. Stables GJ, Young EM, Howerton MW et al. (2005) Small school-based effectiveness trials increase vegetable and fruit consumption among youth. J Am Diet Assoc 105, 252-256.

16. Lowe CF, Horne PJ, Tapper K et al. (2004) Effects of a peer modelling and rewards-based intervention to increase fruit and vegetable consumption in children. Eur J Clin Nutr 58, 510-522.

17. Fogarty A, Antoniak M, Venn A et al. (2007) Does participation in a population-based dietary intervention scheme have a lasting impact on fruit intake in young children? Int J Epidemiol 36, 1080-1085.

18. Di Noia J, Contento IR \& Prochaska JO (2008) Computermediated intervention tailored on transtheoretical model stages and processes of change increases fruit and vegetable consumption among urban African-American adolescents. Am J Health Promot 22, 336-341.

19. Ammerman AS, Lindquist CH, Lohr KN et al. (2002) The efficacy of behavioral interventions to modify dietary fat and fruit and vegetable intake: a review of the evidence. Prev Med 35, 25-41.

20. Pomerleau J, Lock K, Knai C et al. (2005) Interventions designed to increase adult fruit and vegetable intake can be effective: a systematic review of the literature. $J \mathrm{Nutr}$ 135, 2486-2495.

21. Evans CE, Christian MS, Cleghorn CL et al. (2012) Systematic review and meta-analysis of school-based interventions to improve daily fruit and vegetable intake in children aged 5 to 12 y. Am J Clin Nutr 96, 889-901.

22. Glasson C, Chapman K \& James E (2011) Fruit and vegetables should be targeted separately in health promotion programmes: differences in consumption levels, barriers, knowledge and stages of readiness for change. Public Health Nutr 14, 694-701.

23. Greene GW, Fey-Yensan N, Padula C et al. (2004) Differences in psychosocial variables by stage of change for fruits and vegetables in older adults. J Am Diet Assoc 104, 1236-1243.

24. Henry H, Reimer K, Smith C et al. (2006) Associations of decisional balance, processes of change, and self-efficacy with stages of change for increased fruit and vegetable intake among low-income, African-American mothers. J Am Diet Assoc 106, 841-849.

25. De Vet E, de Nooijer J, de Vries NK et al. (2006) The transtheoretical model for fruit, vegetable and fish consumption: associations between intakes, stages of change and stage transition determinants. Int J Behav Nutr Phys Act 3, 13.

26. De Vet E, de Nooijer J, de Vries NK et al. (2005) Stages of change in fruit intake: a longitudinal examination of stability, stage transitions and transition profiles. Health Psychol 20, 415-428.

27. De Vet E, de Nooijer J, de Vries NK et al. (2008) Do the transtheoretical processes of change predict transitions in stages of change for fruit intake? Health Educ Behav 35, 603-618.

28. Carvalho de Menezes M, Bragunci Bedeschi L, dos Santos LC et al. (2016) Interventions directed at eating habits and physical activity using the Transtheoretical Model: a systematic review. Nutr Hosp 33, 586.

29. Conner M \& Norman P (2005) Predicting and changing health behaviour: future directions. Predict Health Behav 2, 324-371.

30. Langenberg P, Ballesteros M, Feldman R et al. (2000) Psychosocial factors and intervention-associated changes in those factors as correlates of change in fruit and vegetable consumption in the Maryland WIC 5 A Day Promotion Program. Ann Behav Med 22, 307-315.

31. Di Noia J \& Prochaska JO (2010) Mediating variables in a transtheoretical model dietary intervention program. Health Educ Behav 37, 753-762. 